\title{
A LOT DONE BUT MUCH MORE TO DO: AN ASSESSMENT OF THE CUBAN ECONOMIC TRANSFORMATION SO FAR
}

\author{
C. Juan Triana Cordoví \\ Centre for the Study of the Cuban Economy, University of Havana
}

\begin{abstract}
The aim of this paper is to provide a brief summary of the last two years of the process of transformation in Cuba from a primarily economic perspective. It consists of five parts: an introduction, which makes it clear that the changes are not merely economic; a first section that deals with the urgent needs of economic development; a second section that seeks to highlight how the process has been gaining in depth and scope and now focuses more on how to define the paths of development than on survival; a third section that evaluates the results in two perspectives, from the dynamics of the process of change and from the country's economic performance in recent years (although with restrictions due to data availability); and conclusions.
\end{abstract}

Keywords: economy, Guidelines, results, performance

\section{Introduction}

Two years after the Lineamientos (Guidelines) were approved as the programmatic document of the changes being made in Cuba it is time to take stock, however brief, of their meaning and what has been achieved.

The transformation undertaken has undoubted precedents that cannot be ignored, but it responds to a reality that is qualitatively different from that which pertained during previous processes, just as it has references to the international situation, but neither are they exactly the same.

The scope of the changes (which the Guidelines have caused) is holistic and has not only led to changes in the economy, but is accompanied by the deepest, and possibly the most questioned, institutional changes that have occurred in the country since the mid-1970s. In fact, these transformations challenge the Cuba of the present and introduce logical questions about Cuba's future. They are not 
only associated with a form of economic operation, but also the political and ideological superstructure that must promote and legitimise it.

They are totally legitimate in the sense that the country that is becoming transformed sustains a society built from a socialism (that of the 1970s and 80s) that replicated patterns generated in Europe and that, after 30 years, failed to generate the means to eliminate the structural deformations of underdevelopment. This society is now moving towards a different socialism, one that is Cuban, to be built upon national conditions that are very different from the European, without a theoretical framework, that closely fits those conditions, and it is doing so at a time when an unquestionable generational transition is taking place. All this implies a paradigm shift even though in essence what is being attempted is to keep alive the socialist ideal.

To draw the contours of this new socialist ideal is not a simple task, and to define the details of its operation is perhaps a difficult goal to achieve due to the very dynamic nature of the changes to be made.

After two years of implementation, it is time to review the progress and the way forward in the coming years. The work below is intended to contribute to that purpose.

\section{From the Confrontation of an Adverse External Environment to a New Conception of Cuban Socialism}

Just as in the case of the process of opening that began in 1990, the trigger for the current updating process is associated with external constraints. Indeed, what we know today as 'the updating of the Cuban economic model' is the direct result of a process that started from the middle of 2007 and had as its genesis the confrontation to an adverse external environment:

Since 2005 the limitations of the economy have been evident: to address the deficit in the financial account of the balance of payments, withholding foreign bank transfers and the high amount of debt maturities, all that meant a great stress in handling the economy. (Guidelines, 2011)

The process initiated in 2007 has passed through stages which have ranged from targeting urgent problems (putting idle land into production, adjusting imports to meet the payments crisis, etc.) and removing a first set of prohibitions (admitting Cuban citizens into tourist hotels, the sale of cell phones, etc.) to the formation of a more comprehensive transformation of the economy and society (The Economic and Social Guidelines), the referendum, the approval process at the different levels of the political direction of the country (and State and Party), the creation of a special institution for the implementation and process 
control (Implementation Commission), the subsequent formation of a ScientificTechnical Advisory Board defining more research work, covering virtually all areas of economic and social life of the country ${ }^{1}$ in which more than 40 research centres and universities around the country are employed. In that sense, it was a process of continuous learning and institutional innovation.

\section{Box 1 Measures taken since the approval of the guidelines}

- Strengthening the institutional framework, including the reorganisation of the state and government.

- Emphasis on the concept that the economic plan must conform to the available resources.

- Prioritising growth and diversification of exports and import substitution, designing special programmes and measures to support the financing of enterprises that allow the use of a currency in a decentralised way.

- Review and reorientation of investment policy to give greater integration and avoid immobility of resources and other inefficiencies. In accordance with this, available external credits have been redistributed towards short-term goals that have most effect on the balance of payments.

- Reprogramming foreign debt payments.

- Transformations in both the structure and the functioning of the agricultural sector; issuance of Decree Law 259 on the delivery of idle state lands in usufruct, with the objective of increasing food production and reducing imports.

- Additional measures for saving energy, including those related to organisational aspects, such as the reorganisation of cargo transport in the country.

- The start of an important number of industrial investments that are strategic in terms of the future development of the country.

- In order to lighten the burden on the state of some services, experiments were initiated such as the replacement of workers' canteens and transport, leasing barbers, hairdressers and taxis to those employed in these activities.

Unlike the process of opening that started in the 1990s, the essential difference of that initiated in 2007 and confirmed in 2011, is the political and ideological assimilation of the need for change as a key aspect of the continuity of Cuban socialism and the relatively open willingness to consider all the variants that would sustain this socialism (still to be defined in detail).

Another element that is implicit in the above is the belief that as well as updating the model and the definition of how the economy should work (the conceptualisation of a working model of the economy) there must appear a sufficiently clear definition of the model of development for the country.

This could be an element that complicates the process in its early years, bearing in mind that models are generally an ex-post outcome, whose defining elements are created from synthesised reality. However, in Cuba, we prefer to 
proceed from the start with a definition ex-ante a working model (something qualitatively different from a vision of the country) requiring details that are difficult to pre-establish given the relatively unheard-of transformations being conducted. This process was defined by the highest leadership as 'a journey into the unknown' (Castro Ruz, 2012).

In this sense, the creation of a sort of triad between the conceptualisation of an economic and social operating model, a model of economic development and a programme of economic and social development in the long term appear as the core of the entire transformation directed by the Guidelines.

Another element that is significant and distinguishes it from previous processes is that it is accompanied by the transformation of the organs and entities of state (ministries, branches and other institutions) and systems of relations between them.

Strictly speaking, the improvement of the institutions of the state anticipated the transformation process of the implementation of the guidelines, with the merger of the Ministries of Foreign Trade and Foreign Investment and Collaboration, then of the Ministry of Food Industry and Fisheries. ${ }^{2}$ Then, in the summer of 2011, came the integration of the two institutions (that which worked on perfecting the state institutions and the one responsible for the Guidelines) in a single 'Development and Implementation Committee of the Economic and Social Guidelines'. This institutional evolution has allowed the integration of the two processes of change that needed to complement each other.

In this way the updating of the functioning of economy and society, accompanied by the transformation of the institutions that should carry it out, is a simultaneous process of successive approximations, which covers all ministries and agencies of the country with the purpose of aligning their missions with the economic and social transformation that the country needs, achieving the correct identification of state functions that these institutions must meet, organising their structures according to their tasks and functions, reducing their workforces, ${ }^{3}$ separating state functions ${ }^{4}$ from business functions and making the decision-making processes more transparent and agile.

This should help to reduce the 'institutional barriers' that the economic transformation could face but, in return, could generate occasional gaps due to slow reaction times and the rearrangement of these same institutions.

\section{From the Emergency to Development}

A review of those first steps that preceded the guidelines permits us to identify them with the need to respond to the emergency facing the country, the balance of payments constraints (a constant since 1990 but that accelerated dramatically 
in 2007 and 2008) and the onset of internal measures to boost agricultural production, etc., in a process of crisis management and survival effort, combined with the removal of bans that were already politically untimely and harmful, and a growing openness to a small private sector.

However, the very dynamics of the process demonstrated the need for a conception that went beyond crisis management and survival in order to project a more comprehensive conception, specifically one that would direct the country's future.

Without doubt, within the Guidelines there are contained, sometimes totally explicitly and sometimes implicitly, important clues to the direction of that future, but more was needed.

The attempt, therefore, as has been stated officially, is to design a country that is desired and that can be achieved. In this design process some important consensuses have been achieved.

\section{A Vision of the Future}

While that key statement that the future is a path to the unknown remains undeniable, the fact is that in these past two years substantial progress has been made in creating a necessary vision that traces the main lines of future development. In this regard some claims by President Raul Castro are significant elements.

\section{Box 2 A vision of the future}

- A sustainable and prosperous socialist society (Castro Ruz, Granma, 2012).

- A less egalitarian but more just society (Castro Ruz, Granma, 2013).

While there is a great agreement as to what is understood by sustainable, it is not so in the case of the concept of prosperity, so that deciding what is understood as a prosperous society becomes an important exercise in order to build the country of the future. The codes that the concept encloses in the case of Cuba should be opened, as a premise of the necessary consensus around the term.

Here again it is easier to approach the concept through negation rather than affirmation. In any case it is important to know generally what the Cuban population today understands as 'prosperity'.

Some questions that can help pave the way are given below:

- What should be the traits that define prosperity in Cuba, understanding that the referents used by Latin American or even the Asian countries that also share the socialist ideal do not fit our reality and needs? 
- Do we accept the concept of prosperity that is determined by the quantitative and qualitative improvement in consumption, especially of individual consumption?

- Do we understand that individual prosperity and collective prosperity are not necessarily synonymous and that there may be differences between the two? What may be the tolerable limit?

- Do we admit and legitimate the economic differences arising from the distribution of work and the existence of other forms of non-state property and sources of income?

- Does this prosperous socialist society admit the possibility of the existence of a middle-income sector? Is it possible today in Cuba, to build this prosperous socialist society without that sector? Is it possible to directly influence the composition of that sector?

From another angle, sustainability is also essential, not only because of the condition of being a small and insular territory, but because, without doubt, the effort to achieve high growth rates makes it hardly possible to maintain the ecological footprint levels found today, which, at 1.9, is much lower than that of other countries with high human development indices (UNDP, 2011).

The growth needed to achieve the desired development will require, as has been the experience of other countries (World Bank, 2004), a strong investment in physical capital in construction, machinery and infrastructure, intelligent management of natural capital, including investment of the income from perishable resources (mining and quarrying, sun and beach tourism, etc.), rebuilding the existing 'human capital' and encouraging the creation of new 'human capital' adequate to the vision of the future, investing in intellectual capital in order to better assimilate the advances of science and modern knowledge and to slow or reverse the declining supply of skilled labour. All this compromises sustainability, yet, better conditions for achieving this goal can be created.

\section{Development as a condition for the continuation of Cuban socialism}

It is clear now more than ever that the continuity and modernisation of Cuban socialism is linked to the progress and consolidation of economic and social development. What has changed is the way to see this relationship. Years ago the idea was held, not only in academic circles, that 'socialism is not possible without development'; today, however, as a result of recognising the international experience, the phrase is constructed exactly in the opposite way, 'development is not possible without socialism'. 
We are now trying, as has been proposed by the leadership of the country, to build a development programme. It is not an easy exercise, especially in the conditions of Cuba. Two important aspects of this effort are to recognise the multidimensionality of development and plurality of the participation of the different actors and forms of ownership.

Obviously, other elements associated with external constraints, where the US blockade has a prominent place will have to be considered.

\section{Growth as a condition of development}

Also here the positions have changed dramatically, from those that at some point (and against all the evidence) held that it was possible to develop without growth, towards recognising the reality and admitting that the aspiration to develop necessarily involves growth rates significantly higher than those achieved in the last three years.

Policy makers have to choose a growth strategy, communicate their goals to the public, and convince people that the future rewards are worth the effort, thrift, and economic upheaval. They will succeed only if their promises are credible and inclusive, reassuring people that they or their children will enjoy their full share of the fruits of growth. (World Bank, 2008, p. 3.)

In general, experience shows that from both the quantitative and qualitative points of view it is necessary to deal with three key aspects in the growth process: pay attention to all activities, physical, human and natural; attend systematically and continuously to the distributional aspects and to emphasise the institutional framework for good governance (Thomas, Dailami et al., 2000).

Growth is critical in our two key aspirations, progress towards development and building socialism. If the economy is not growing at an adequate rate it will not generate enough resources to eliminate the structural distortions that have tied Cuba to underdevelopment, and neither will it achieve the ability to distribute according to work and create a richer society, spiritually and materially.

However, growth in any form or in any sector is also not desirable; real growth requires a specific form of growth (gain accelerated productivity) and in sectors that enhance spillovers and linkages to the rest of the economy. Growth should encourage and be the carrier of the necessary structural change (Torres, 2011) that will permit us to exploit the advantage of the highly qualified Cuban labour force (Cribeiro, 2012) and reduce the disadvantage of the population ageing dynamic that is typical of a developed country in conditions of underdevelopment and significantly lower productivity rates. 
In this effort to grow we cannot forget the external constraints. In this way, growth must also be compatible with the possibility of managing the external debt (Quiñones, 2012).

This is also how the welfare border will be extended, ensuring the sustainability of Cuban socialism, after decades managing scarcity.

\section{A high rate of investment as a critical factor for growth}

Clarity has also been achieved with regard to the need for investment. Achieving high rates of investment and gross capital formation is the way to grow. But what typifies the national economy is a kind of perverse dynamic between low levels of savings (of families and the state) and low levels of consumption of both.

The reduction in household consumption as a way to increase saving and investment does not seem possible, nor does it seem that a reasonable reduction of state consumption would provide the resources to substantially raise the investment rate.

\section{Foreign investment as an important element for development}

Clarity seems also to have been gained with regards to the consideration of foreign investment, not as a complementary resource, but as an essential element of the investment rate (Pérez Villanueva and Vidal Alejandro, 2012). However, legislative adjustments to facilitate the attraction of that resource are not yet ready.

This is one aspect where the balance between the political cost and economic benefit is most sensitive. It should not be forgotten that until very recently Foreign Direct Investment (FDI) was conceptualised as a necessary evil.

However, what has been proved by more than 20 years' experience of FDI in Cuba, is that the benefits in terms of improved productivity, efficiency, the conquest of foreign markets and gains derived from improvements in management are beyond doubt. Even when the country's institutional framework itself (Villar and Rodríguez, 2012) prevented a better use of the effects, by significantly reducing their leverage and limiting the expansion of the real wages of workers in the companies involved in these projects. ${ }^{5}$

\section{Institutional modernisation as a requirement to accompany the development}

Without doubt this is one of the most important consensuses reached. It is understood here as institutional modernisation - not only the transformation of institutions (ministries, bodies, etc.) but also of the entire legal and regulatory system. 
The impact of institutional changes on growth and development seems, today, to not require any new demonstration. Efficient institutions to ensure transparent processes are a prerequisite for the aspiration of development.

Unlike purely capitalist economies, the Cuban economy is tied essentially to planning, a process which in itself requires relatively powerful institutional processes, ${ }^{6}$ but the fact that the market is also playing an increasingly significant role in the dynamics of the economy, reinforces the need for an appropriate institutional framework. 'In practice, every one of the successful market economies is supervised by a multitude of regulatory institutions in the financial market and in those of goods, services, labour and assets' (Rodrik, 2000). Even more, therefore, in a socialist economy that requires supervision of market relations.

In the 1990s, one of the factors that drove the recovery of the Cuban economy was associated with the liberalisation process introduced at the start of the decade. Its positive impact through increases in Total Factor Productivity has been proven (Doimeadiós, 2007). Other studies have shown a close relationship between the cycles of centralisation and decentralisation and the growth dynamics of the national economy (Vicente, 2004).

These are key issues for the present and the future. Without a doubt, an essential element of the desired future is a smaller but strategically stronger state that focuses on the decisive, economic driving instruments which allow indirect but effective regulation of the economy and with efficient bureaucracies concentrated on the mission of each institution.

In this sense it is important to underline the fact that institutions not only matter, but also take time to build (Rodrik, 2000) but without them, the whole economic transformation effort will be at best ephemeral.

\section{Results}

The results can be categorised into two types: those that express/confirm the progress of the process itself and those that have a quantifiable expression in the performance indicators of the economy.

\section{The advance of the process}

With regard to the first, in the last two years the country has undergone a number of changes in all spheres of economic and institutional life. What is truly remarkable is the orderly manner in which they have been made, and the fact that even when some of these organisational changes have been major and have often led to profound changes in the structures that support these organisations, they, nevertheless, have remained operational. 
The intensity of this process is beyond doubt if you examine their quantity and quality.

\section{Box 3 The advance of the Guidelines}

- The railway development programme, the purchase and sale of homes and motor vehicles, increased self-employment, including the most recent measure of leasing state eateries, the entry into force of the producers selling to agricultural tourism entities, the 17 measures that modify and update the operation of cooperatives, putting them on equal footing with other forms of production, Decree Law 300 amending the previous 259 for delivery of land in usufruct.

- (...) The adoption of legal frameworks to give support to what is implemented, not only of what is shown above, but also in the case of 126 non-agricultural cooperatives, the creation of the Superior Business Development Organisations, (...), the restructuring of central government agencies, the design of better and more streamlined organisational structures, both supporting the delimitation of state functions and of the business.

- (...) The banking policy of the country with the entry into force since December 2011 of Decree Law 280 which gives the possibility to access credit (...) The reform of the tax system under Law 113 from 1 January seeking a better distribution of wealth generated by the country.

- (...) The experiment in the province of Artemisa and Mayabeque as part of the improvement of the People's Power (Granma, 15 April 2013).

In this sense, 2013-14 will be decisive for the transformation process as at least four of these policies should begin to have an impact in the short and medium term and play vital elements of the economy. They are:

1 The new tax law.

2 The beginning of the entry into force of amendments to the migration law.

3 Experiments with business in the state sector.

4 The beginning of the experimental operation of cooperatives in the non-agricultural sector.

The new tax law attempts a difficult balance between the objective of introducing a tax culture in the population that has access to reduced income, a purpose manifestly aimed at tax collection, based on the tax burden rather than the expansion of the tax base, an intention to stimulate the new private sector and as a policy to avoid the 'concentration of wealth', something difficult to achieve even with this new law, which sets at 50,000 pesos per year $(2,083$ convertible pesos per year or 173 per month) the amount of revenue from which the self-employed must pay 50 per cent of the income received. This constitutes a limit for working capital creation and the expansion of those businesses from equity. 
Undoubtedly, in this case, the great dilemma is not fiscal or redistributive, but conceptual; it is trying to make coherent the idea of limiting the concentration of wealth to the practice of creating a middle-income sector capable of job creation and of assuming productive commitments to supplement the state sector as well as creating new 'chains' that contribute to the improved efficiency and productivity of the system.

The question is how do you do that if, on the one hand, the technological complexity of the self-employed is limited and, on the other, limits are also set on private accumulation capacity, essential for improving the quality of those jobs and new businesses? In this case the allowed maximum non-taxable income to 50,000 Cuban pesos leaves little room for the 'new businesses' to consolidate, weakens potential sources of private domestic accumulation and favours 'imported' accumulation through remittances.

The other negative effect is associated with the stimulus to tax evasion via underreporting or using 'proxies' or 'leasing' undeclared equipment and resources. The fiscal arrangement and associated policies will undoubtedly be matters to reconsider at some future time.

The entry into force of changes in the migration law is one of the facts that demonstrate the political will in the process.

The migration changes can positively impact on remittances, as they foster temporary departures to seek work in addition to reducing the pressure on the Cuban labour market, where employment is growing today via the non-state sector because the employment generation capacity of the state is very reduced.

The possibility that any Cuban, (save the exceptions that probably do not amount to 1 per cent of the population), can travel freely and come back when it is most convenient (for which they only need to update their passport every two years) will mean that Cuba will become a systematic 'sender' of tourists for the first time in 50 years. This may have a significant impact on the current account balance, if only in tourism revenues in the months of July and August when Cubans with sufficient income (who are the main customers of domestic hotels in those months) can go sightseeing in other Caribbean islands at prices even lower and with much better services than those offered in Cuban facilities.

However, overall, the balance of this measure is clearly positive in the political sense and for the image of the country, but also for the Cuban family and its likely effect on the increase in remittances, as well as by the relative relief on the demand for jobs.

The changes to be introduced in the state enterprise system are clearly the most significant because the country's economy and a substantial portion of employment are concentrated in these. The experiment will include a small number of companies and Higher Business Management Organisations, 
Corporations, Self-Funded Research Centres and High Technology Companies. This small number of companies, (Azcuba, GAEFAR, Biocubafarma, etc.) are critical in the Cuban economy. In fact, 70 per cent of the profits produced in the country are concentrated in less than 6 per cent of all enterprises, and almost all of them are included in this process.

The idea is to increase the autonomy and authority in economic and financial management of these state enterprises, an old unattained goal dating back to the 1970s when Cuba began its first 'opening' under the Management of the Economy System.

Among its goals are: allowing the recapitalisation of companies, using part of the increase in profits to improve workers' wages, promoting the creation of a wholesale market as they allow firms to freely sell any surplus over the state target and to make sure that international prices are correctly reflected in the costs of domestic firms - all of which are common functions to any company in the world, but not allowed, or significantly limited, in Cuban state enterprises.

Another change focuses on the procedures for approval of the 'social purpose' of a company, one of the biggest barriers to business competitiveness in Cuba. In the new philosophy, approval will be in the hands of the body or organ that constitutes the company, whereas previously the duty was held by the Ministry of Economy and Planning. Also this social purpose does not have to define the currency in which the company will operate, an issue that in the previous philosophy was necessary and substantially limited their possibilities, to which is added that it is the director of the company or entity who will decide the secondary activities of the enterprise, all issues that are currently in the hands of the Ministry of Economy and Planning.

After experimentation from 2013 to 2016, the experiment will be extended to the rest of the business system and will help to develop the new Companies Act. The division of the system into companies that are in the experiment and others that are not may introduce important deviations and bottlenecks that could adulterate the real meaning of what has been achieved, on the other hand, waiting three years to launch the Companies Act may bring significant costs for the purposes of improving the process of reforms and their impact on the performance of the economy.

Another aspect to consider is the time factor. While experimenting is the 'logical' way, the time it will take to get to the generalisation and a new Company Law in Cuba could conspire against another of the purposes of the updating process - to achieve high economic growth rates.

The other important measure in 2013 is the creation, also experimentally, of cooperatives in the non-agricultural sector, more than 200 in the first stage. State agricultural markets (about 111) will become cooperatives, together with the 
trucking companies and others in construction, making a total of 126 that have already been approved.

Again, the promotion of cooperatives in areas that will generate more employment for a wide range of qualified Cuban professionals is still awaited, resulting in opportunity cost to the national economy.

Furthermore, the mechanism designed for their creation requires a long road of intermediate decisions and ends in the approval by the Implementation Committee. It is to be hoped that after the initial experiments the procedures for creating cooperatives will be more expedient.

What is new for Cuba is that the decree regulating its operation also stipulates that the award of state contracts will be through a competitive bidding process, a practice not at all usual in the country.

\section{The behaviour of the economy}

Two years is a relatively short time, we will examine below some of the variables of economic performance.

In terms of economic growth, the most important is in the fact that we could maintain an economic growth momentum despite having implemented a strong policy of adjustment to imports.

However, the average rate achieved in the last four years is relatively low and is far from the real needs of the country.

In the qualitative aspect, we see better results. On the one hand, growth is concentrated in the productive sectors, especially in 2012, on the other, even if the execution of the investments remains poor, their relocation is seen in the

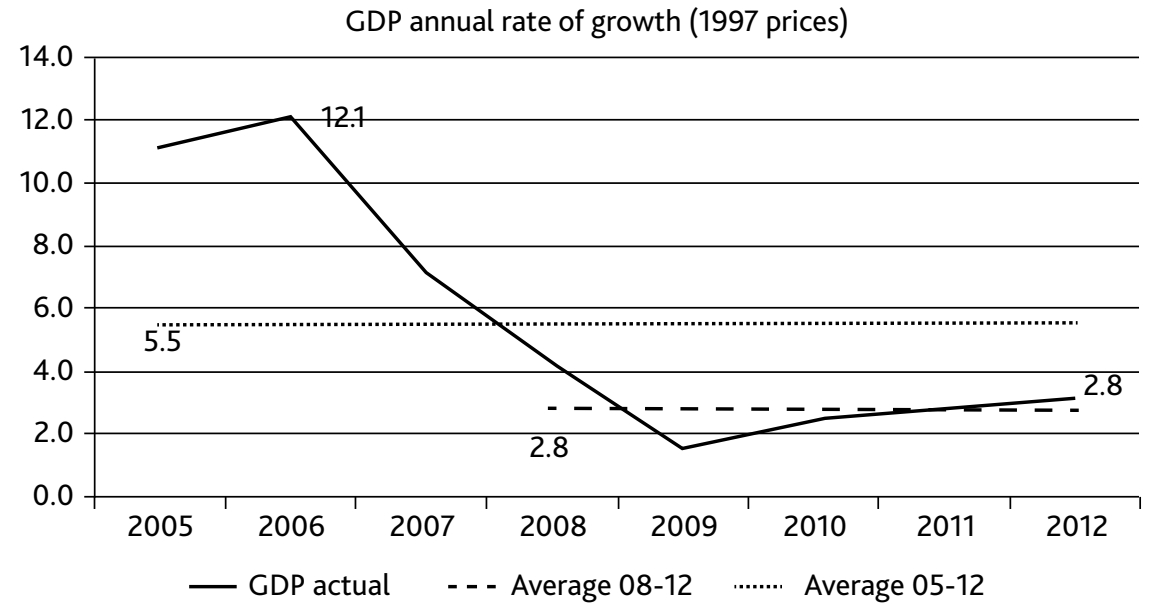

Figure 1 Behaviour of GDP 
tradable productive and service sectors, something which the country needed and that is consistent with the need to recover the Cuban productive sector.

One positive sign is that the productive sector grew by 4.5 per cent. However, agricultural production reached only 2 per cent of annual growth, an insufficient dynamic, increasingly demonstrating the strong need for capital injections into the sector. But other sectors did better, for example, 4.4 per cent in manufacturing, 20 per cent growth in sugar production, 5 per cent in transport and communications, 5.9 per cent in trade. Oil, gas and nickel also increased at levels similar to the previous year. Tourism, without reaching the planned growth targets, maintained a positive momentum, to arrive at 2.85 million visitors, representing a growth of 4.9 per cent compared to the previous year (Martínez, 2012).

As in 2011, the investment plan was not met. However, the investment structure again favoured the productive sector, consolidating the government's policy of promoting the economy of the island.

Gross fixed capital formation is still very low (between 10 and 11 per cent when it should be over 25 per cent). The only option that the country has in the short term to increase savings is to resort to foreign capital, something already fully accepted today but still facing indisputable prejudices that are difficult to remove quickly.

This is an issue of particular importance for the productive recovery. The data on the situation of Cuban industry confirms a significant deterioration that is impossible to solve with domestic investment.

Table 1 State of the Industry

Index of physical volume of industry by the destination of the products $(1989=100)$

\begin{tabular}{lrrrrrr}
\hline Sector/Group & 2006 & 2007 & 2008 & 2009 & 2010 & 2011 \\
\hline General Index & 38.7 & 40.2 & 46.1 & 44.9 & 43.6 & 45.1 \\
Consumer goods & 67.7 & 71.8 & 78.9 & 80.5 & 77.8 & 82.8 \\
Food, drink and tobacco & 68.2 & 72.7 & 73.7 & 75.0 & 66.3 & 74.1 \\
Consumer manufactured goods & 66.5 & 69.4 & 92.6 & 94.9 & 107.9 & 105.3 \\
Domestic hardware & 86.7 & 82.3 & 90.2 & 97.5 & 93.9 & 94.8 \\
Shoes, clothes and confectionery & 15.4 & 16.2 & 17.9 & 19.6 & 18.8 & 24.7 \\
Other consumer goods & 116.7 & 124.4 & 174.5 & 176.3 & 208.7 & 195.8 \\
Capital goods & 5.3 & 11.8 & 14.8 & 8.5 & 6.6 & 6.6 \\
Metallic structures & 22.2 & 31.3 & 18.2 & 20.6 & 24.3 & 22.8 \\
Transport equipment & 0.8 & 9.0 & 19.8 & 5.6 & 0.3 & 0.1 \\
Machinery and other goods & 0.2 & 1.7 & 4.0 & 4.0 & 3.8 & 5.2 \\
Intermediate goods & 29.9 & 31.2 & 38.4 & 36.3 & 36.7 & 37.4 \\
Energy & 24.5 & 27.4 & 71.1 & 63.5 & 61.9 & 59.1 \\
Materials for construction & 28.5 & 29.7 & 24.9 & 23.0 & 25.5 & 28.0 \\
Extraction and transformation of materials & 153.9 & 156.7 & 151.1 & 150.3 & 150.2 & 155.6 \\
Other intermediate goods & 23.0 & 23.8 & 26.2 & 25.2 & 25.5 & 26.2 \\
\hline
\end{tabular}

Source: ONEI, 2011. 
As can be seen, the weakness of the sectors that produce capital goods and intermediate goods is significant and compromises any recovery effort, because the weak complementarity of the Cuban industrial sector decreases its capacity to absorb investments and reduces their multiplier effect.

This also explains, at least in part, GDP growth's high sensitivity to imports, and gives an idea of the industrialisation effort that the country needs which, in turn, makes industrial policy decisions paramount. ${ }^{7}$

Another important result is associated with the generation of employment. In the past two years, it is the non-state sector, especially the self-employed sector (bigger yet) that has been the only source of employment in the country, with more than 200,000 new jobs created in 2011 (ONEI, 2012). This also has a positive impact on individual and family life because, unlike a few years ago, now there are ways to significantly improve one's income and quality of life without resorting to out-migration, something very positive if one considers the demographic constraints facing Cuba. It is well known, however, that while there are restrictions on the expansion and growth of this type of employment towards more technologically complex sectors and those heavier in 'knowledge', it will remain a 'partial and limited' solution and will not contribute sufficiently towards development, in conditions of a restrained state investment effort.

There is also an intangible outcome associated with the diversification of the supply of goods and services alternative to the state sector but legal, with the creation of relatively stable 'supply chains' (especially in the case of supplies of agricultural products to restaurants) demonstrating the feasibility of decentralisation.

From the perspective of balances, this expansion of the demand of a sector that produces 'non-tradables' to an economy with high inelasticity of supply could generate significant inflationary pressures in the short and medium term, with negative impacts that reinforce losses in real wages.

In the external sector in 2011, exports were 97.8 per cent of that predicted for the year. Although there are no official data, among the export goods, nickel, petroleum and pharmaceuticals maintained their leadership, even though nickel production fell short of its potential with the closure of one of its plants due to technological obsolescence and low mineral production. It is also likely that the prevailing strong import restrictions even have a negative impact on exports.

Taking into account the structure of trade in 2011 it can be said that the most relevant change is found in products such as drugs and biopharmaceuticals, which in 2011 exceeded $\$ 500$ million, and possibly oil derivatives, which have become the new flagship Cuban exports.

As for imports, food and fuel comprise large items. In fact, the Cuban government has maintained tight control over imports of goods, trying to reduce the current account deficit. In 2012, imports decreased by 2.8 per cent. 


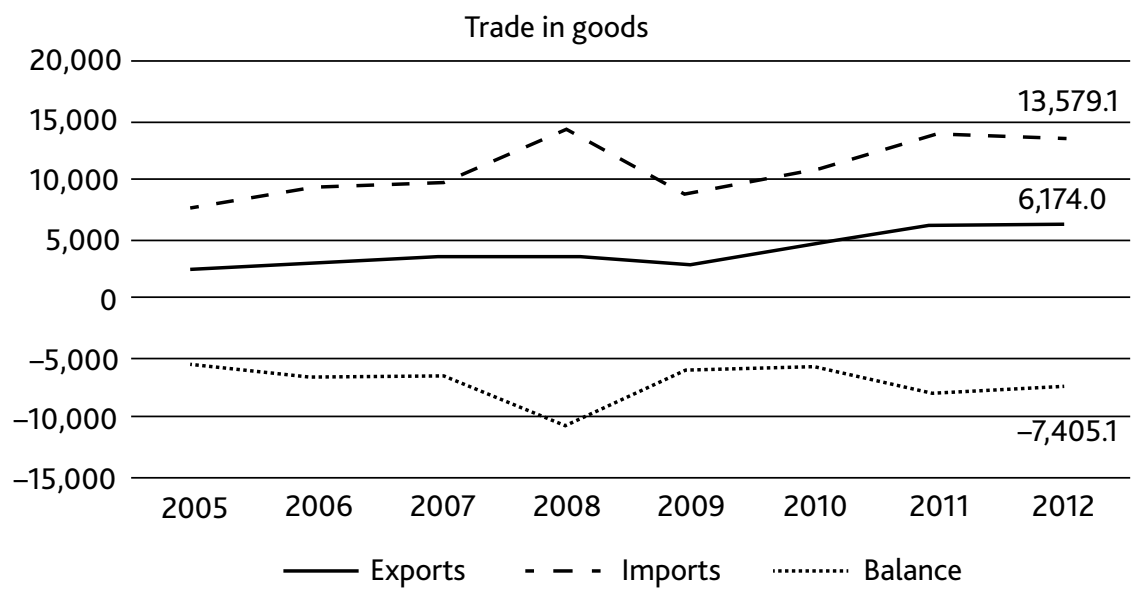

Figure 2 Trade balance

Table 2 Export performance by type of goods

Merchandise exports by product (millions of pesos)

\begin{tabular}{lrrrrr}
\hline & 2007 & 2008 & 2009 & 2010 & 2011 \\
\hline Total & $3,685.7$ & $3,664.2$ & $2,863.0$ & $4,597.7$ & $\mathbf{6 , 0 4 1 . 0}$ \\
Products of the sugar industry & 203.0 & 235.8 & 226.4 & 266.2 & 388.8 \\
Products of mining & $2,081.3$ & $1,434.3$ & 839.3 & $1,190.6$ & $1,414.3$ \\
Products of the tobacco industry & 236.1 & 234.5 & 212.3 & 202.2 & 223.4 \\
Products of fishing & 83.9 & 73.6 & 45.7 & 59.5 & 66.4 \\
Products of farming & 15.0 & 15.2 & 14.5 & 14.1 & 20.9 \\
Other products* & $1,066.4$ & $1,670.8$ & $1,524.8$ & $2,865.1$ & $3,927.2$ \\
\hline
\end{tabular}

(*) Biotechnological, pharmaceutical and derived from oil Source: Office of National Statistics, 2012.

The export of services must have stayed favourable considering that tourism revenues, which account for about 20 per cent of total service revenues, grew by 4.7 per cent in 2012 and it is anticipated that the income from medical services, of which exports to Venezuela are the main source, increased or maintained a similar dynamic to the previous year.

The structure of trade by countries, both in exports and imports should not have changed significantly in relation to 2011 .

The relevance of the last two years in exports of goods is the importance attached to the Venezuelan market, which must be associated with two types of products, petroleum products and generic pharmaceuticals and biotechnology. 


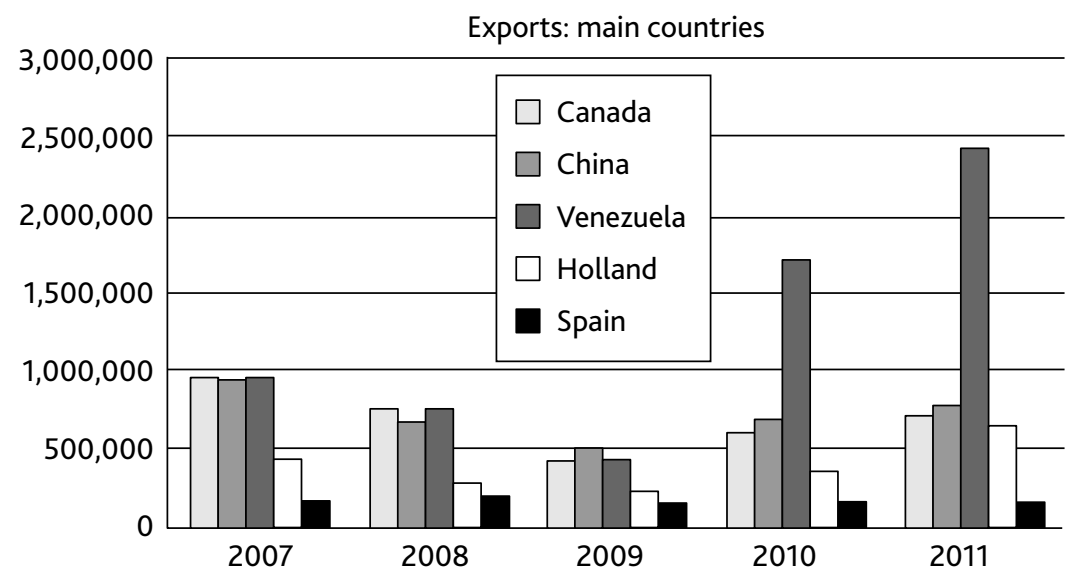

Figure 3 Principal export markets by country (convertible pesos)

Imports: main countries

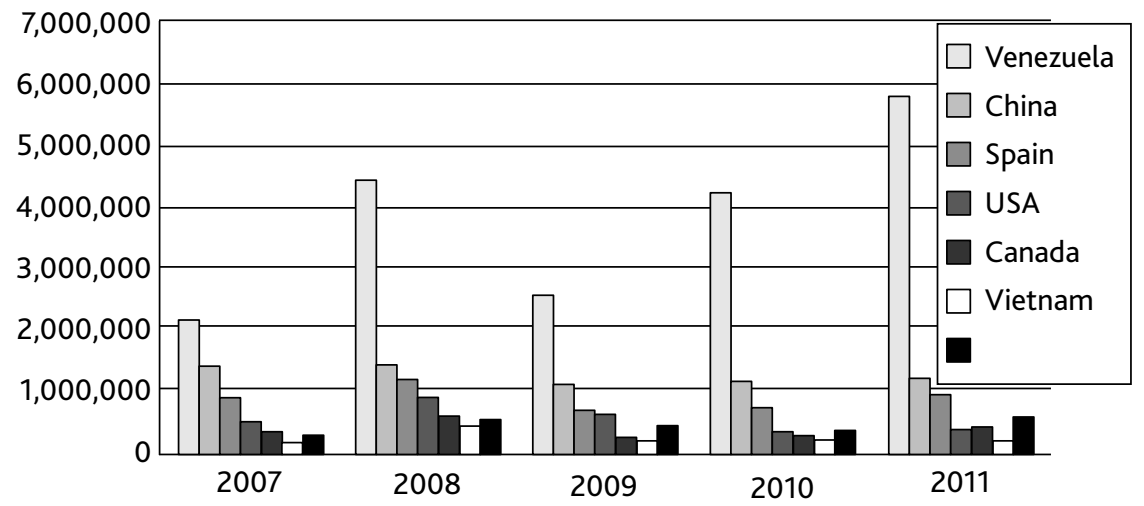

Figure 4 Principal origins of imports by country (convertible pesos)

Similarly, without the 2012 data it is also possible to assume that Cuba imports will have the same origins as in 2012. Venezuela, because of the sale of oil to Cuba, China, because of loans tied to different types of products, and Spain will remain the major vendors.

The country's current financial situation appears relatively stable, according to the Economist Intelligence Unit estimates for 2012 which highlight the stability of the trade deficit, because of the restrictions the government has placed on imports and the relative stability of the deficit in account. In short, this is a sign that the government has made a final decision to maintain external financial balances in the short term (Table 3). 
Table 3 Current financial situation: leading indicators (in millions of pesos)

\begin{tabular}{lrrrrrr}
\hline & $2008^{a}$ & $2009^{a}$ & $2010^{a}$ & $2011^{b}$ & $2012^{b}$ & $2013^{c}$ \\
\hline Balance of goods & -10.570 & -6.043 & -6.049 & -7.915 & -7.910 & -7.845 \\
Exports & 3.664 & 2.863 & 4.598 & 6.041 & 6.285 & 6.678 \\
Imports & -14.234 & -8.906 & -10.647 & -13.956 & -14.195 & -14.523 \\
Balance of services & 8.637 & 7.192 & 6.985 & 8.202 & 8.021 & 7.815 \\
Balance of income & -1.055 & -1.201 & -1.520 & -1.626 & -1.491 & -1.647 \\
Balance of current transfers & 482 & 476 & 781 & 1.179 & 1.195 & 1.272 \\
Balance of current account & -2.506 & 424 & 197 & -160 & -187 & -405 \\
\hline
\end{tabular}

${ }^{a}$ Actual. ${ }^{b}$ Economist Intelligence Unit estimates. ${ }^{c}$ Economist Intelligence Unit forecasts.

The Central Bank of Cuba has published the 'outstanding debt' of Cuba until 2009 (Table 4).

Table 4 Active debt (in millions of pesos)

\begin{tabular}{lrrrcc}
\hline 2009 & Total & Short term & $\%$ & Medium and long term & $\%$ \\
\hline Total debt & $\mathbf{1 2 , 3 1 0 . 2}$ & $3,133.0$ & 25.5 & $9,172.2$ & 74.5 \\
Official debt & $5,884.3$ & $1,497.6$ & 25.5 & $4,386.7$ & 74.5 \\
Bank debt & $1,835.5$ & 467.1 & 25.4 & $1,368.4$ & 74.6 \\
Debt to suppliers & $4,590.4$ & $1,168.2$ & 25.4 & $3,422.2$ & 74.6 \\
\hline
\end{tabular}

While these data are not current, they already reflect a more favourable debt structure in 2009 , as the medium and long term had greater weight in the total 'active' debt.

The behaviour of the total debt, according to the Economist Intelligence Unit, reflects a moderate increase in the foreign debt and the payment of principal. This can be interpreted as a good sign in the sense that Cuba has recovered, at least in part, international credibility and is now eligible for credit.

Table 5 External debt and international reserves (in millions of pesos)

\begin{tabular}{lrrrrrr}
\hline & $2008 a$ & $2009 a$ & $2010 a$ & $2011 a$ & $2012 b$ & $2013 c$ \\
\hline Accumulated debt & 19.645 & 20.223 & 20.536 & 21.520 & 22.161 & 22.700 \\
Payments for debt services & 1.571 & 1.864 & 2.062 & 2.050 & 2.134 & 2.221 \\
Principal payments & 897 & 1.088 & 1.224 & 1.249 & 1.340 & 1.398 \\
Interest & 674 & 776 & 838 & 801 & 793 & 824 \\
Total international reserves & 3.693 & 3.893 & 4.093 & 4.393 & 4.693 & 4.743 \\
\hline
\end{tabular}

${ }^{a}$ Actual. ${ }^{b}$ Economist Intelligence Unit estimates. ${ }^{c}$ Economist Intelligence Unit forecasts.

From another angle, to a country like Cuba, with a strong relationship to double dependency, both between economic growth and growth in imports 
and between export growth and import growth, it is very difficult to think of removing the debt in the short and medium term, where it is more feasible to think of ways to reconcile economic growth needed and sustainability of the external debt (Quiñones, 2012).

Achieving growth targets in 2013-14 (3.7 per cent) will depend, in part, on a group of factors outside the influence and control of our country. First, again any significant change in the blockade conditions can have a significant impact on the economy. The behaviour of the European economy in the crisis should impact on the behaviour of the national economy directly, through tourism, as Europe remains our main market after Canada, and indirectly through the movement of food prices. The evolution of the situation in Venezuela is also an important element in the dynamics of the national economy. After electing Maduro, the situation is much clearer, however, a drastic reduction of the relationship could cause a contraction of the Cuban economy between 4 and 9 per cent (Vidal, 2013) in the first three years, even if Cuba managed to compensate for the loss of the services market in Venezuela almost immediately.

Table 6 Growth projections for 2013

\begin{tabular}{lc}
\hline Principal economic indicators $2013(\%)$ & \\
GDP & 3.70 \\
Deficit & 3.60 \\
Unemployment & $3.8-4$ \\
Consumer price index & 1.60 \\
Agriculture & 4.50 \\
Manufacturing & 4.70 \\
Sugar production & 21.70 \\
Tourist revenues & 8.50 \\
Tourist arrivals & 12.50 \\
Investments & 34
\end{tabular}

Expected growth, although higher than that of 2012, is still below what is required for national economic growth. Restrictions on the supply side and still weak external investment flows will continue to limit higher productive performance.

The increases agreed for the agricultural sector are also far from the real needs. It is in agriculture where the largest source of immediate import substitution is found, however, despite the advances in the delivery of land and other policies, the productive sector remains weak (Nova, 2013). The increase in sugar production is also limited, also compromising export revenues. Tourism revenue may also be reduced if we look at the figures for the first two months (January-February 2013), where arrivals were nearly 2 per cent lower than expected. 


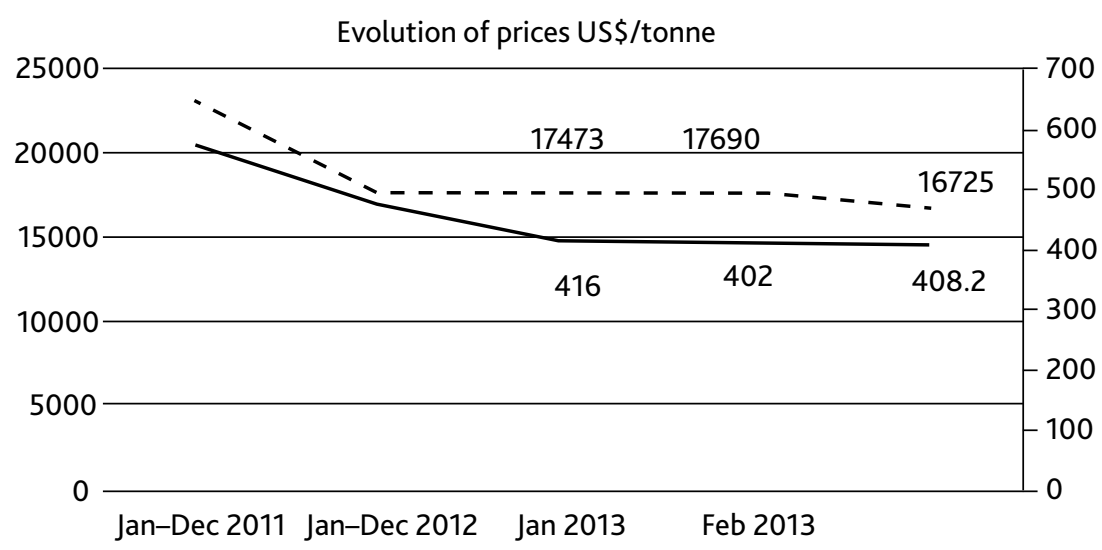

- - - Nickel \$/tonne _ Sugar \$/tonne

Figure 5

The evolution of the price of nickel and sugar is not entirely favourable, although in the case of sugar its evolution and prospects are better than nickel.

The planned production volume in the case of nickel in 2013 does not offset the decline in prices. In the case of sugar, failure to achieve the targeted volume of raw sugar will also negatively affect foreign exchange earnings.

In this situation, the relationship with Venezuela is again critical to ensuring export revenues of both goods and services.

Regarding the implementation process, as has been said, 2013 is crucial as the implementation of major changes in the state enterprise system start to take effect. This, in turn, will impact on macroeconomic variables, for companies entering the experiment will be able to use depreciation to retain up to 50 per cent of profits and use them relatively freely, possibly as working capital, research, development and innovation, investment and wage stimulation. To some extent, it may produce an upward adjustment of wages in these companies, according to performance, which indicates a way to increase the nominal wages of workers and could become 'a way' to do so in the state enterprise system. According to estimates, the real wage in 2012 was 27 per cent of that in 1989 (Vidal, 2013).

Similarly, when operating in Cuban pesos an exchange rate (between 10 and 11 pesos per US dollar) would permit adjustment of the type of exchange in a step by step process to eliminate distortions in efficiency and productivity that exist today. It cannot be denied, however, that the partial introduction of a new exchange rate can also generate other distortions (for that same partial character) and even inflationary expectations in other sectors of the economy. There is therefore no easy road. 


\section{Conclusions}

The decision to continue the transformation is firm, its pace in part depends on internal developments, but also on external conditions over which Cuba has no control.

2013-14 should be a year of growth (3.7 per cent) but will be marked by uncertainties beyond the control of the country.

The growth rate is lower than that required to promote the structural changes that will enable progress towards sustainable development and achieve a prosperous society.

We should not expect significant changes in the distribution of income in favour of workers in the state sector in the short term, however, there must be specific improvements in this regard in a group of companies.

Nor should we expect substantial improvements in labour productivity significantly impacting economic growth. Nonetheless, the changes that have been introduced can contribute to that purpose, albeit modestly.

The country will continue to face significant financial constraints as indicated by the evolution of the price of nickel and sugar in 2012 and their prospects for 2013-14. Substantial increases in these prices are not expected and this, together with the limitations in the production of both products, restricts the provision of foreign exchange of the country.

Changes to foreign investment law are an urgent necessity, delay increases the opportunity costs and has a negative effect on growth and the structural transformation of the economy.

The agricultural sector continues to lag. Its growth rate is insufficient and threatens the country's financial capacity.

The expansion of self-employment towards more technologically complex segments and those with higher knowledge content is a possibility to improve systemic productivity and change the structure of employment in this sector, delivering gains in productivity and efficiency.

Continued institutional changes should also contribute to improvements in efficiency and productivity. This includes changes in state organisations, the 'way of doing things' and the management of macroeconomic policies.

It is necessary to create an environment conducive to growth and investment, national (state) and foreign. Similarly, it is necessary to encourage taking advantage of the 'assets' created, stimulating research and development, which would in turn enable productivity gains, the expansion of the efficiency frontier for the existing capital resources of the economy and incorporate the non-state sector (cooperative and private) much more strongly into the purpose of economic growth.

(Translated by Stephen Wilkinson) 


\section{Notes}

1. The results of which are 'inputs' into the decision-making process.

2. It should be remembered that in the middle of the 1990s a similar exercise was carried out and the number of state institutions with the rank of a ministry was reduced from 50 to 25 .

3. Of the five million workers in the country more than 50 per cent are concentrated in the budgetary sector.

4. Also in the 1990s there was an explicit plan to separate the state functions from business, which was not achieved, although it should be noted that the Ministry of Tourism managed a way to run very close to that goal, which was unfortunately lost in later years.

5. The differential between wages paid by foreign companies to the Cuban employment offices and the salaries those offices pay to the Cuban employees of the foreign firms, is a brake on the expansion of real demand. It also has other costs associated with the 'rentier' character of the measure, as well as issues associated with corruption, etc. Moreover, the overall change in the scenario of the country, with the impetuous dynamic of a non-state sector, especially the self-employed, concentrated in activities of low productivity that can earn large incomes (between 50 and 100 Cuban pesos per day), while the workers in the foreign companies, almost all located in strategic sectors (with salaries that do not exceed 700-800 Cuban pesos per month) questions the economic and political desirability of maintaining such a situation.

6. The role of planning is not being questioned here, it is only being affirmed that it will remain one of the basic elements of future socialism and, as such, requires a defined institutional framework.

7. Of which, the promotion of productive chains is only part.

\section{Bibliography}

Castro Ruz, R. (13 December 2012). Granma.

Castro Ruz, R. (24 February 2013). Granma.

Cribeiro, Y. (2012). Contribución de la fuerza de trabajo calificada en Cuba al crecimiento económico. Principales determinantes. Doctoral Thesis.

Doimeadios, Y. (2007). El crecimiento económico en Cuba: un análisis desde la productividad de los factores. Doctoral Thesis. Havana, Cuba: Facultad de Economía.

Martínez, O. (14 December 2012). Dictamen sobre el Plan de la economía nacional y el presupuesto del Estado para el año 2013. Cuba.

Nova, A. (25-27 June 2013). Un nuevo escenario, un nuevo modelo agricola y de gestión económica cubano. Seminario Anual del Centro de Estudio de la Economía Cubana. (CEEC, Ed.) Havana.

ONEI. (2012). Anuario Estadísico de Cuba 2011. Havana.

PCC. (2011). Lineamientos de la política Económica y Social del Partido y la Revolución. Havana: Communist Party of Cuba.

Pérez Villanueva, O., \& Vidal Alejandro, P. (2012). La inversión extranjera directa y la actualización del modelo económico cubano. Havana: Centro de Estudios de la Economía Cubana. 
Quiñones, N. (2012). El deficit externo de Cuba: un análisis desde la sostenibilidad. Doctoral Thesis. Havana: Facultad de Economía, Universidad de la Habana.

Rodrik, D. (2000). Estategias de Desarrollo para el próximo siglo. Developing economies in the 21st century. Chiba: Institute for Developing Economies, Japan.

Thomas, V., Dailami, M., et al. (2000). The Quality of Growth. (World Bank, ed.) Washington, DC: Oxford University Press.

Torres, R. (2011). Cambio Estrucutral y Crecimiento Económico en Cuba. Doctoral Thesis. Havana: Centro de estudios de la Economía Cubana.

UNDP. (2011). Informe sobre desarrollo humano 2011. Sostenibilidad y equidad: iun mejor futuro para todos. UNPD. New York: UNPD.

Vicente, Y. (2004). Marco institucional, influencia en el crecimiento productivo en Cuba. Diploma Thesis. Havana: Facultad de Economía, Universidad de la Habana.

Vidal, P. (May 2013). Ponencia presentada en Latin America Studies Association Congress. Washington, DC.

Villar, L., \& Rodríguez, V. (2012). El proceso inersionista y la financiación de inversiones en Cuba:deficiencias, limitaciones y retos. Economía y Desarrollo, 148(2), 124-138.

World Bank. (2004). Responsible Growth for the New Millennium: Integrating society, ecology, and economy. Washington, DC: World Bank.

World Bank. (2008). Informe sobre el Crecimiento: estrategias para el crecimiento sostenible y el desarrollo incluyente. Washington, DC: Mayol Ediciones S. A. 